\title{
Back to Back Connected Multilevel Converters: A Review
}

\author{
Amit Ojha ${ }^{1}$, Pradyumn K. Chaturvedi ${ }^{2}$, Arvind Mittal ${ }^{3}$, Shailendra K. Jain ${ }^{4}$ \\ ${ }^{1}$ (Department of Electrical Engineering, MANIT, Bhopal, ${ }^{2}$ (Department of Electrical Engineering, SATI,Vidisha \\ ${ }^{3}$ (Department of Energy, MANIT, Bhopal, ${ }^{4}$ (Department of Electrical Engineering, MANIT, Bhopal
}

\begin{abstract}
The new power converter topologies i.e multilevel converter is major breakthrough in power conditioning applications. The role of multilevel converters for AC-AC conversion when connected Back to Back is now proving an achievement of mile stone in the field of high power conversion. In view of this a comprehensive review of Back to Back connected multilevel converters is presented in this paper, which focus mainly on its topologies, control strategies and real time industrial applications. The aim of this review is to group and review the recent publications, in order to establish the current state of the art and trends of the Back to Back connected multilevel power converters (MPCs) to provide researchers meaningful information about this technology.
\end{abstract}

Keywords- Bi-directional converters, BTB connection, Front End Converters, Improved Power Quality, MPCs, Multilevel Topologies, SPWM.

\section{Introduction}

AC-AC converters, used in application ranging from few MW to several MW are playing key role in the field of power conditioning. AC-AC converters are broadly classified based on direct conversion (direct link) or indirect conversion (dc link). The former one i.e. phase controlled cycloconverters (direct link converters) having a big disadvantage of generation of complex harmonics in load and line along with poor line DPF. Whereas the later one i.e. dc link converters in which two converters connected back to back through dc link is an effective way to get variable frequency in the output with reasonably good power quality[1].

The front end converter in dc link AC-AC converter as shown in Fig.1 may be either line commutated converter or active front end converter. But the line commutated front end converter is suffering from serious problem of power quality issues such as injection of harmonics in to the system \& requirement of reactive power [2]. So the choice available is active front end converter for the rectification [3].

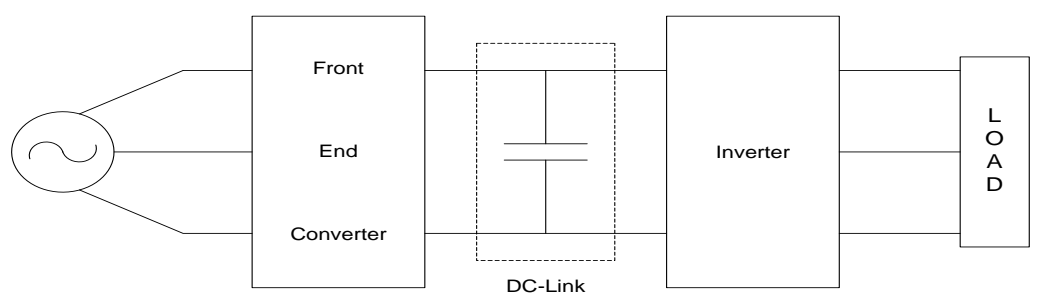

Fig.1 AC-AC converter

However there is an acute competition between the use of classic power converter topologies (2-level) using high voltage semiconductors [4] and new converter topologies (multilevel) [5, 6] using medium voltage devices in high power applications as shown in Fig.2.

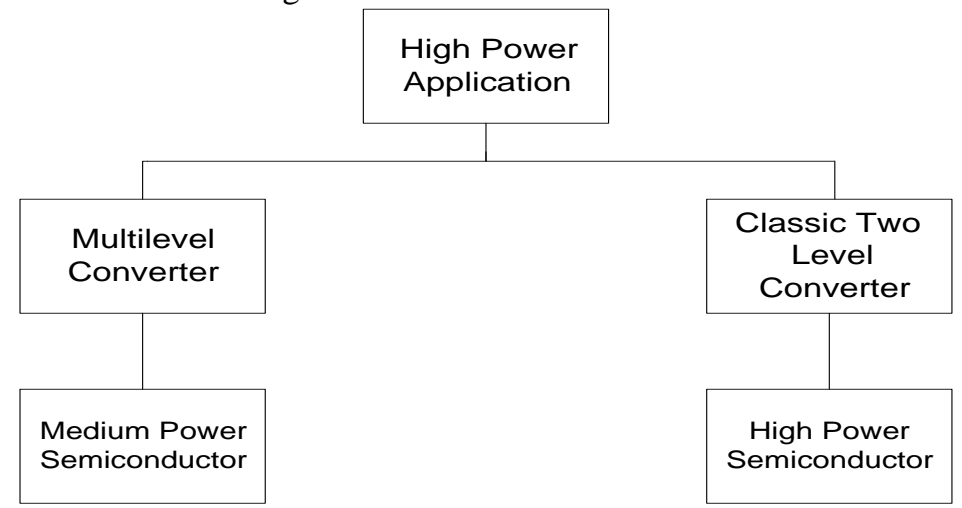

Fig.2 Classification of semiconductor family for high Power Application

Large dv/dt, device voltage stress, common mode voltage, high switching frequency etc. are reasons for using multilevel converters in dc link AC-AC converters (converters connected Back to Back) in place of 2-level 
conventional converters. Multilevel power converters are now finding increased attention in industry and academia as one of the preferred choices of electronic power conversion for medium/high power application [4] like high power AC motor drives. The main objective of using multilevel converter in high power application is to eliminate heavy costly transformers from the motor drive. Another advantage of using multilevel converters are nearly sinusoidal current waveform, lower common-mode voltage \& lower $\mathrm{dv} / \mathrm{dt}$ that lead to reduce stress on motor bearings \& windings $[8,9]$.

Looking in to the importance of multilevel converter in AC-AC conversion, this study is carried out to provide concrete information about this technology. In this review more than 70 papers are studied. All these papers basically deal with multilevel converters, their topologies \& their control for specific applications.

The paper is organized as follows: The need for Back to Back connected converters is discussed in section II. A brief overview of multilevel converter topologies is outlined in section III to present basic concepts. Section IV gives information about the components required for AC-AC conversion in which MPCs are connected Back to Back. Section V covers the latest trends in multilevel modulation technique for BTB connections. New and future promising applications of multilevel converters using BTB connection are described in section VI. Challenges before this technology is covered in section VII followed by concluding remarks in section VIII.

\section{Need of Back to Back Connected Multilevel Power Converters}

With the advancement in the field of power electronics it has been well established that multilevel inverter is the most widely used static power converters for alternating current applications which includes variable speed industrial electric drives, electric vehicles, reactive power compensation in large distribution and transmission systems, electric traction drives and interfacing of renewable energy sources (photovoltaic and fuel cell) with the utility. Many of these application required bidirectional operation of the multilevel converters [10]. Unfortunately, the standard diode/thyristor rectifiers at the input side have serious problems of low input power factor, high THD in input currents and harmonic pollution on the grid. There is one literature [11] in which performance of 3-level neutral point clamped rectifier is compared with 2-level conventional rectifier in terms of input power factor, input current THD and ripple factor of the regulated dc output voltage. The study shows that multilevel rectifier for proposed control scheme is far superior to its counterpart 2-level rectifier and gives better performance like unity input power factor, negligible input current THD, reduced rippled regulated dc load voltage at a lower switching frequency and reduced voltage stress of the power semiconducting devices. These benefits of multilevel rectifier over conventional rectifier make multilevel rectifier a favorite choice as a DC source for multilevel inverters. This sort of connection of multilevel converters for AC-DC-AC conversion is commonly known as Back-to-Back Configuration (BTB) as shown in Fig.3. There is another advantage of BTB configuration is that, it provide power controllability at both machine and grid side. Looking in to the significant role of Back to Back connection technology for high power applications in industries, this study is carried out to provide concrete information about this technology.

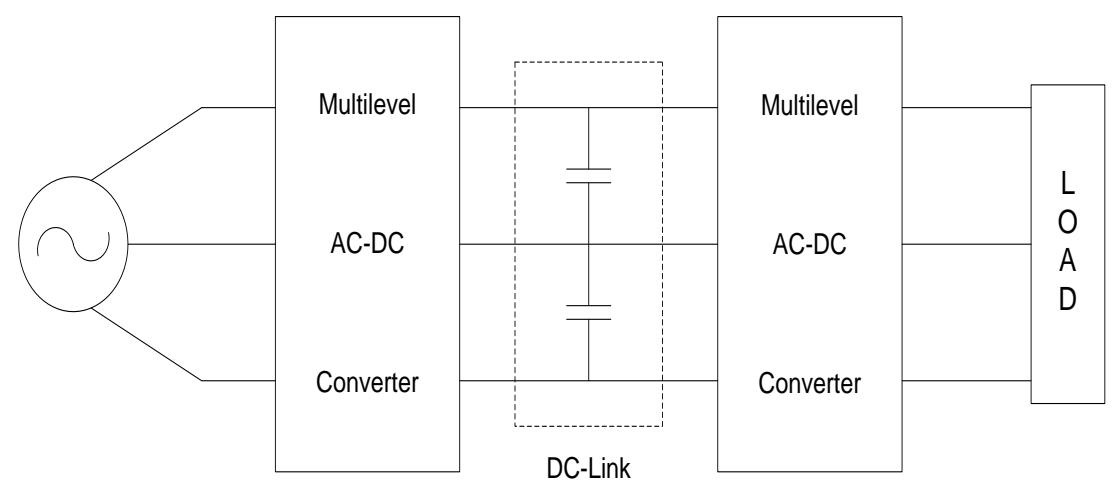

Fig.3 Back to Back connected multilevel converters.

III. Multilevel Converter Topologies for Back to Back Connection

MPCs topologies are classified on the basis of number of phases and power flow capability as shown in the Fig.4. There are two categories, first category consists of single phase and three phase non regenerative MPCs whereas second category consists of single phase and three phase regenerative MPCs. 


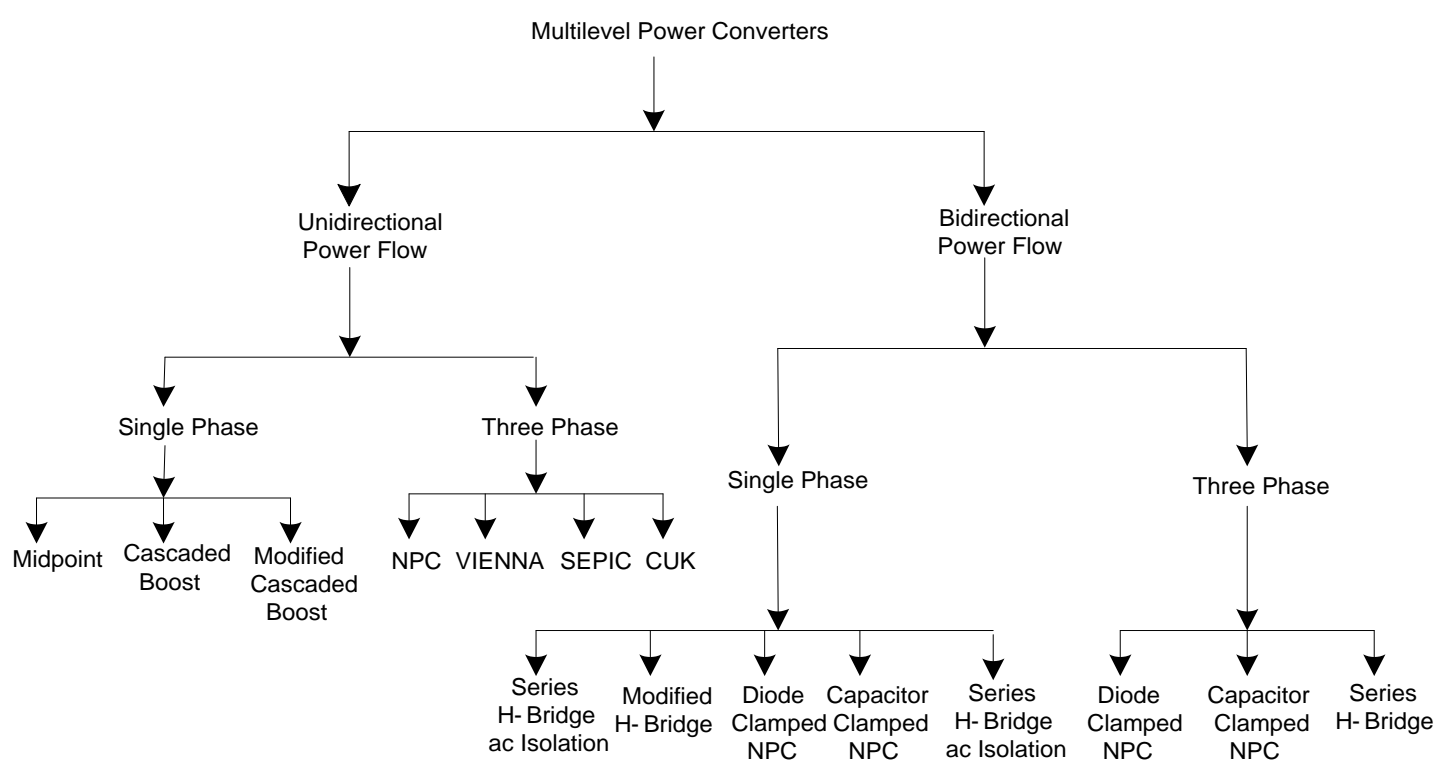

Fig. 4 Classification of power multilevel converters [12]

In order to focus the content of this paper on Back to Back connection of converters for high power applications and ongoing research in this field, well-established three phase bi-directional topologies will only be briefly introduced and referred to existing literature.

\section{i) Diode clamped MPCs}

This circuit configuration provides excellent control over power flow and most adopted topology in real time applications [12-17]. Three and five level diode clamped bi-directional converter is shown in Fig.5 \& Fig.6 which addresses the important issue of unequal sharing of voltages in clamping diodes in diode clamped converters with higher number of levels. Back to Back connected diode clamped converters (Fig.10) provide four-quadrant operation with inherent neutral point voltage balance and is most applied topology for ac motor drives and utility applications.

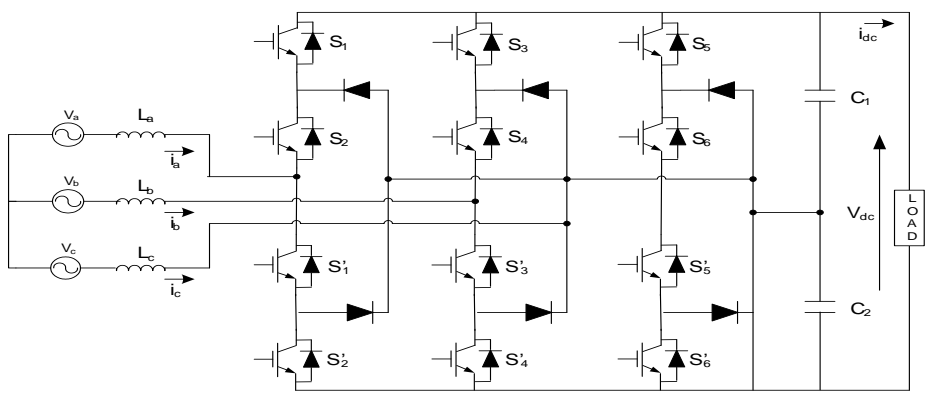

Fig.5 Three level diode clamped bi-directional converter

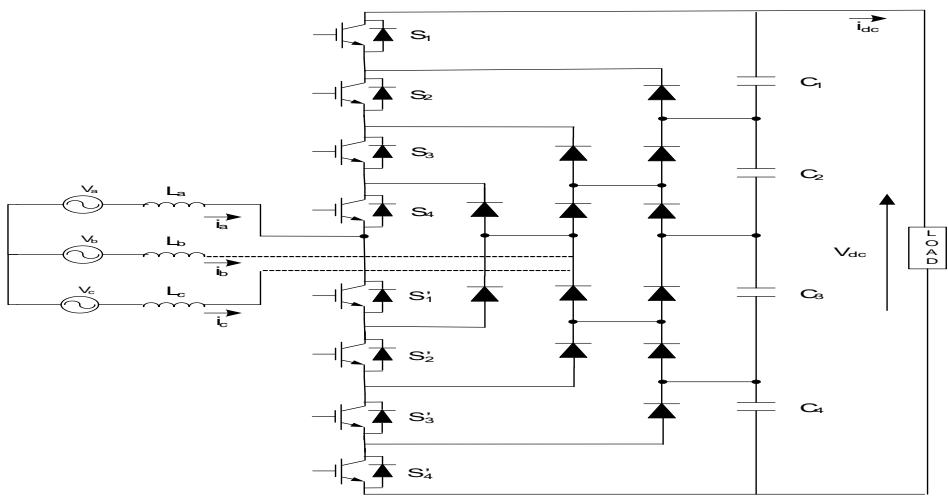

Fig.6 Five level diode clamped bi-directional converter 


\section{ii) Capacitor clamped MPCs}

This is basically modification of diode clamped topology, which is proposed to simplify the neutral point voltage balancing and to eliminate clamping diodes. But the problem in this topology is that the power flow is very much complex and pre-charging of capacitors for ac-dc operation requires dedicated circuitry [12, 13]. The scope of this topology for high power applications is limited due to large current stresses on the capacitors. Three and Five level flying capacitors bi-directional converter is shown in Fig.7 \& Fig.8.

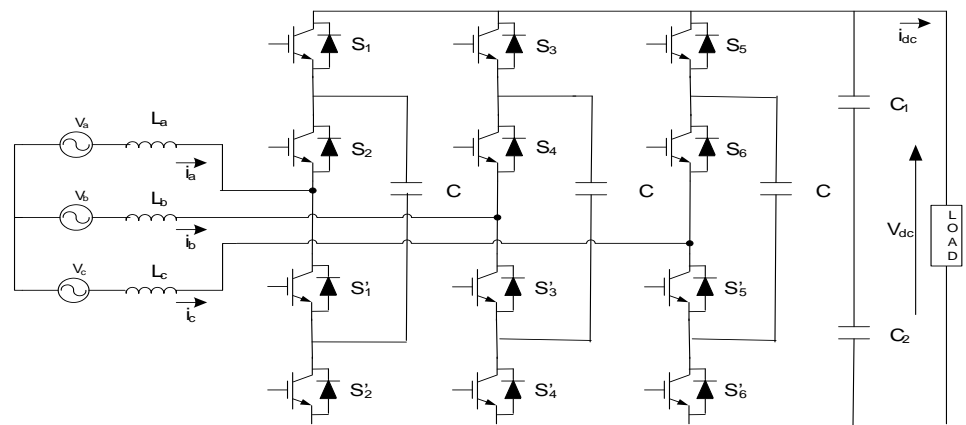

Fig.7 Three level flying capacitor bi-directional converter

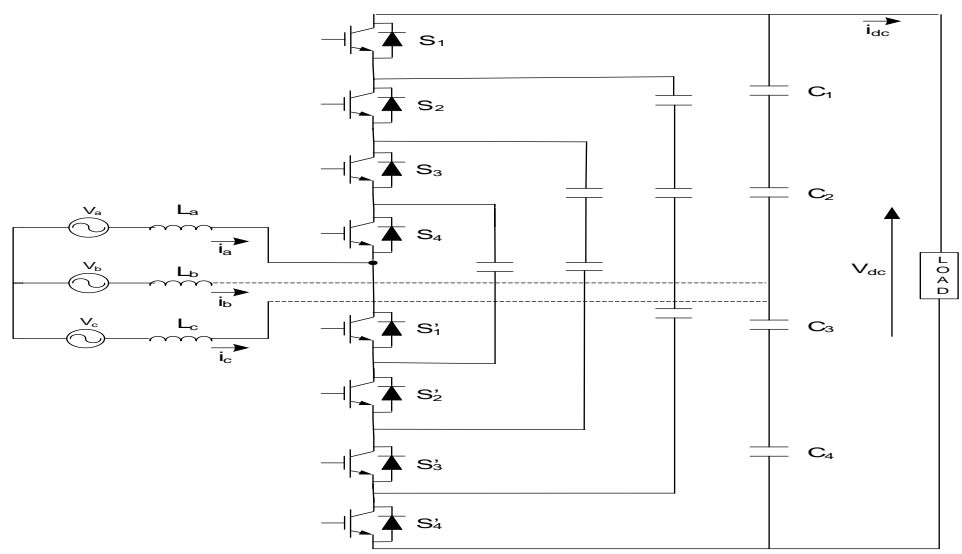

Fig.8 Five level flying capacitor bi-directional converter

iii) H-Bridge converter

Another important topology is $\mathrm{H}$-bridge converter which requires isolated dc source for each level[12,13,18]. It finds its application in inverter fed electric vehicle drives and grid interface for PV generators where isolated dc sources are available. Fig.9 shows one leg of series H- bridge converter with dc link isolation.

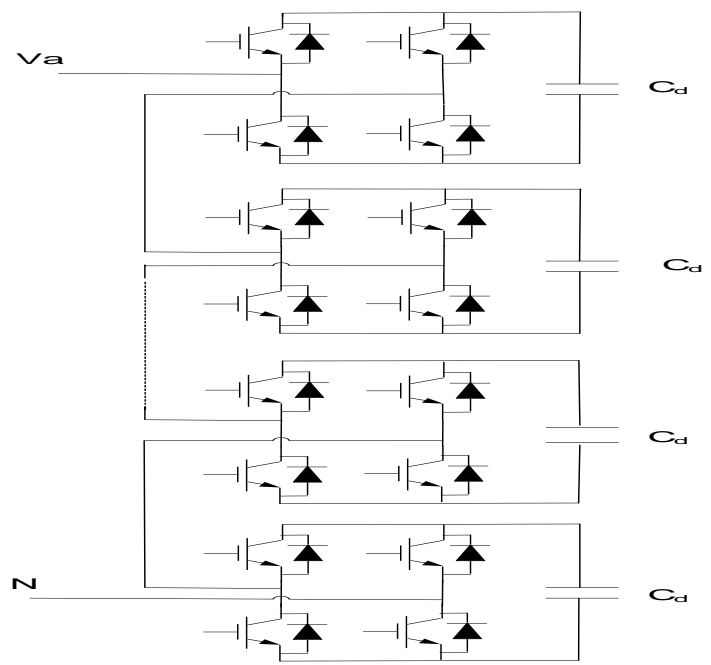

Fig.9 One leg of series H- bridge converter with de link isolation. 


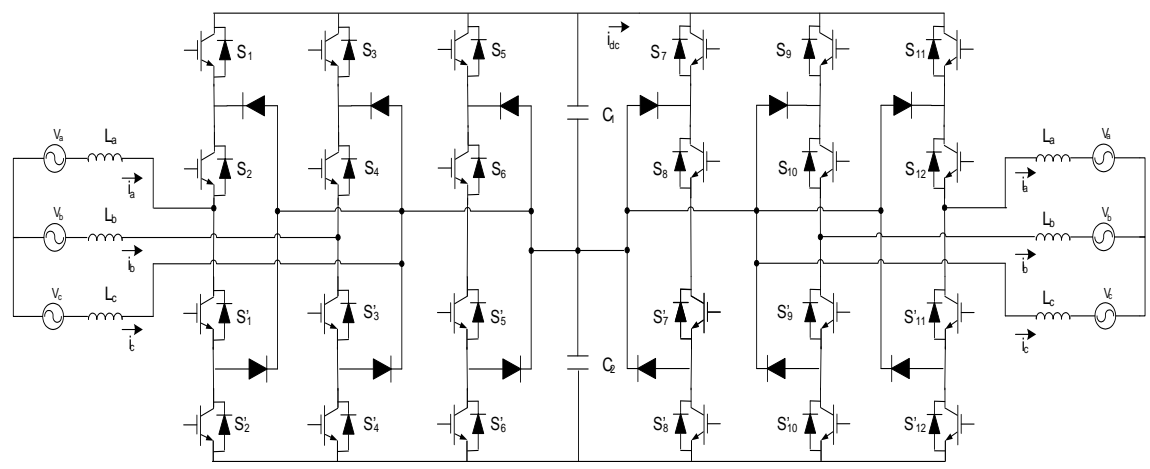

Fig.10 Back to Back connected diode clamped converter

These converters are commercialized by several manufacturers [19-32], offering different power ratings, front-end configurations, cooling systems, semiconductor devices, and control schemes, among other technical specifications. Significant features of three phase bi-directional MPCs are summarized in Table.1.

Table 1

Summary of three-phase bi-directional MPC topologies ${ }^{[7]}$.

\begin{tabular}{lccc}
\hline \multicolumn{1}{c}{ Topology } & $\begin{array}{c}\text { Diode-Clamped } \\
\text { (3-Level) }\end{array}$ & $\begin{array}{c}\text { Capacitor-Clamped } \\
\text { (3-Level) }\end{array}$ & $\begin{array}{c}\text { Series H-Bridge (Isolated } \\
\text { dc link) 3-Leve }\end{array}$ \\
\hline Number of Power Switches & 12 & 12 & 8 \\
Switch Diodes & 12 & 12 & 12 \\
Clamping Diodes & 6 & 0 & 0 \\
Clamping Capacitors & 0 & 3 & 0 \\
Dc Link Capacitors & 2 & 2 & 3 \\
High Side Switches & 9 & 9 & 4 \\
Neutral Point Voltage Balance & Complex & Simple & Very Simple \\
Transformer & No & No & Dc link isolation \\
Redundancy & No & No & Yes \\
Modularity & Complex & Complex & Simple \\
Bi-directional Power Flow & Simple & Complex & Very Complex \\
Figure & 5 & 7 & 9 \\
\hline
\end{tabular}

Operating principles, multilevel waveform generation, characteristics, modulation schemes and other relevant information about these topologies are very well explained in the earlier publications [33-41], therefore it is not covered in this paper. The diode clamped topology is most used topology as it requires reduced number of energy storage capacitors and lack of multiple isolated DC power supplies, when it is compared with flying capacitors topology and cascaded H-bridge topology respectively. Lot of literature is available with diode clamped topology for Back to Back connection, though it is having worse power quality issue [6]. The problem of power quality in diode clamped topology can be reduced by increasing the number of levels and by selecting proper control technique which is presented in section $\mathrm{V}$.

\section{Components of Back to Back Connected Multilevel Power Converters}

The power circuit of MPCs connected Back-to-Back consists of several solid state power devices such as diodes, MOSFET, IGBT, IGCT etc and series connected capacitors. Table 2 highlights the recent development \& contribution of power devices, controllers, and sensors etc required for the reliable operation of MPCs connected Back to Back.

Table 2

Summary of Components of MPC connected Back to Back

\begin{tabular}{|c|c|c|c|}
\hline & Components & Important Features & $\begin{array}{l}\text { Manufacturers } \\
\text { /Model }\end{array}$ \\
\hline $\begin{array}{l}\text { Power } \\
\text { devices }\end{array}$ & $\begin{array}{l}\text { New solid state } \\
\text { self commutating } \\
\text { devices such as } \\
\text { MOSFETs, } \\
\text { IGBTs, GTO, } \\
\text { IGCT, Silicon- } \\
\text { Carbide Power }\end{array}$ & $\begin{array}{l}\text { Devices with high power ratings and low } \\
\text { conduction losses. Availability of high voltage } \\
\text {,high frequency } \mathrm{SiC} \text { devices. }\end{array}$ & $\begin{array}{lr}\text { ABB, } & \text { Renesas, } \\
\text { IXYS etc. } & \text { The } \\
\text { DARPA } & \text { Wide } \\
\text { Bandgap } & \\
\text { Semiconductor } \\
\text { Technology High } \\
\text { Power Electronics }\end{array}$ \\
\hline
\end{tabular}




\section{Devices}

Controllers DSPs,

Microcontrollers,

PLDs,

FPGA,dSpace etc.

Availability of high speed DSP optimised for solving complex algorithms in real time drive application. Important feature of the high speed DSP is its low cost.Low cost PLDs (programmable logic devices) is the best option available for non-linear controllers which replaces the lookup table stored in the memories of slow digital processors.FPGA is characterised by its short design cycle, low cost and high flexibility in terms of programmability.

Sensing Voltage \& Isolated hall effect current and voltage sensors devices Current Sensors

Device drivers
Power drivers are available which are very much required for the reliable operation of MPCs due to the use of digital controllers

device

High performance isolated power devices drivers and hybrid ICs are being now commercially available.

program is
spearheading the
development of HV-
HF SiC power
semiconductor
technology [38]
Texas Instruments
Inc.,
VeriSilicon,Vitesse
Semiconductor
Corporation,Analog
Devices, XILINX,
Lattice
Semiconductor,
NEC, QuickLogic
etc
LEM,Lindsey,MAG
NELAB,Electrohms,
Honeywell,Rongtec
h Industry
(Shanghai) Inc.,
ENTES etc.
SCHURTER, Avago
Technologies,
SEMIKRON,
ARCEL,FAIRCHIL
D semiconductor,
CLARE etc.

\section{Control Strategies of Multilevel Power Converters}

The control strategy of MPC is the heart of the whole system, it actually decide the performance of MPC designed for particular application. The basic aim of the control is to produce multilevel voltages with good spectral quality in MPCs. By this review the authors tried to present some of the important and recent development in the field of control of MPCs used for Back to Back connections. As the control part plays an important role in the working of MPCs, it is worth to present some of the basics for the effective implementation of the control strategy. Normally control is implemented in following three steps.

i) Sensing of variable used in control like voltage, supply current, output dc voltage etc.

ii) Implementation of control algorithm responsible for the high level transient and steady state performance of MPCs.

iii) Deriving of the gate signals for the solid state devices.

It is found in the review that multilevel power converters require explicit control of capacitor voltages to avoid unequal voltages due to symmetrical charging and discharging of capacitors [43-46]. Unwanted harmonics in output voltage waveforms will appear due to the loss of neutral point voltage balance (NPVB) and capacitors can fail if this unbalance leads to voltage stresses beyond their rated limits. An important method for NPVB involves embedded NPVB control in the modulation strategy involving use of redundant switching state [45, 47, and 48]. The important modulation techniques used in multilevel power converter can be classified as shown if Fig. 11

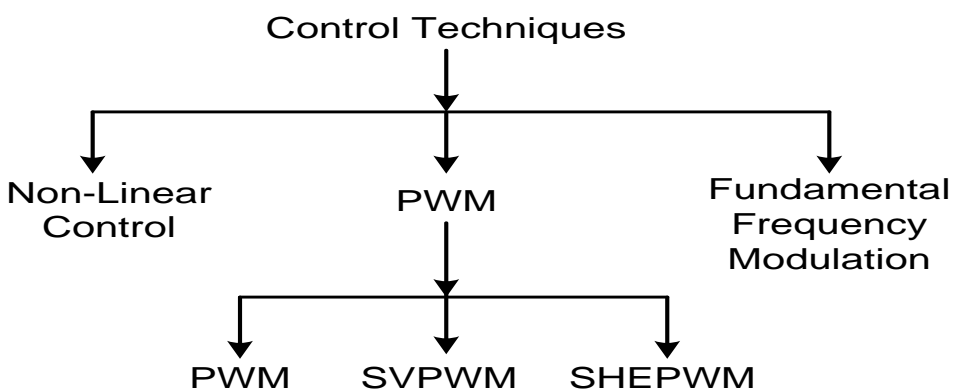

Fig.11 Classification of control techniques for MPCs connected Back to Back. 
Not all the modulation techniques are suitable for each topology of multilevel converters [7]. Table 3 show, which modulation technique is suitable for different multilevel converter topologies. This will be important for selecting particular modulation technique for BTB connection of multilevel converters.

Table 3

Applicability of modulation technique to MPCs topologies.

\begin{tabular}{cccc}
\hline Topology & $\begin{array}{c}\text { Diode-Clamped } \\
\text { (3-Level) }\end{array}$ & $\begin{array}{c}\text { Capacitor-Clamped } \\
\text { (3-Level) }\end{array}$ & Series H-Bridge \\
\hline Space Vector PWM & $\mathrm{Y}$ & $\mathrm{Y}$ & $\mathrm{Y}$ \\
Level Shift-PWM & $\mathrm{Y}$ & $\mathrm{Y}$ & - \\
Phase Shift-PWM & $\mathrm{N}$ & $\mathrm{Y}$ & $\mathrm{Y}$ \\
Hybrid Modulation & $\mathrm{N}$ & $\mathrm{N}$ & $\mathrm{Y}$ \\
Selective Harmonic & $\mathrm{Y}$ & $\mathrm{Y}$ & $\mathrm{Y}$ \\
Elimination & & $\mathrm{Y}$ & $\mathrm{Y}$ \\
Space Vector Control & - & $\mathrm{Y}$ & $\mathrm{Y}$ \\
Nearest Level Control & - &
\end{tabular}

Y- Applicable, N- Not Applicable, - Applicable but Not Recommended

A large number of researches have already been documented in the area of control of MPCs. More than 50 publications have been reviewed and classified in this study to explain the vital role of control in the multilevel converter technology for AC-AC conversion. Some of the important publications particularly deals with the control of MPCs, connected Back to Back are tabulated in Table 4. and the idea behind this is to provide the information about recent advances in control technique used for MPCs, connected Back to Back.

Table 4

Recent advances in control technique for MPCs connected Back to Back.

DC voltage control strategy for a five-level converter

Balancing the DC capacitor voltage divider in backto-back multilevel converters

Limits of the neutral-point balance in back-to-backconnected three-level converters

NPP regulator reducing voltage and current harmonics along with the second harmonic.

Dual 5-Level Inverter-Fed Induction Motor Drive with CMV Elimination and DC-Link Capacitor Voltage Balancing using Switching-State Redundancy-Part II

Back-to-Back Connected Five-Level Diode-Clamped PWM Converters for Motor Drives

Conventional SVM technique has been compared with the single-phase modulator for multilevel converters

A space vector PWM modulation scheme for BTB Methodology

Using simplified control scheme based on SPWM [11]

SPWM with carrier frequency of $3 \mathrm{kHz}$ and voltage balancing control of the common four dc capacitors connected in series using buck-boost choppers [49]

Control circuit uses multiband hysteresis comparators to simplify the control of the main circuit [50]

A new method to balance dc bus capacitors voltages by exploiting the redundant space vectors and using the dc bus average power flow direction [51]

Explorers the limitations of NP current control for balancing the voltage in 3-level NPC converters [52]

Using Simple carrier-based neutral point potential regulator for three-level diode clamped inverter [53]

A simple control scheme based only on the switching state redundancy is proposed as a solution to the operating limitation of the open loop control scheme [48]

DC link voltage can be balanced by using two bidirectional buck-boost choppers [54]

The single-phase modulator for multilevel converters [55]

Proposes a modulation strategy for back to back 
three-level diode-clamped converters

Switching loss analysis of modulation methods used in neutral point clamped converters

Reduction of switching losses due to redundant vectors in SVPWM modulation technique to allow for capacitor balancing in BTB configuration

Control electronic platform based on floating-point DSP and FPGA for a NPC multilevel back-to-back converter

Frequency reduction schemes for back-to-back connected, diode-clamped multilevel converters

Balancing of DC link voltage for Diode -Clamped five level Back to Back connected five level converters

Reduction of switching losses in Hybrid-Clamped multilevel inverters.
NPC converters[56]

A tool where switching losses can be calculated for different modulation technique[57]

To overcome this problem, a switching scheme has been proposed in which not only balances the DC-link capacitors but also reduces the switching frequency [58]

Design, implementation and test of novel real time controller for a NPC 3-level multilevel converter based on floating point DSP and on FPGA by operating in co-operative way[59]

Two new switching schemes for BTB DCC proposed. Result shows $35 \%$ reduction in switching frequency along with the balanced voltage across the DC-link capacitors [60]

A novel SPWM modulation control method is proposed for balancing of Dc-link voltage of multilevel converters connected back to back[61]

A novel PWM control method is proposed which reduces the devices switching on-off within broad range of modulation index[62]

The study clearly shows that SVPWM technique is the most studied technique for Back to Back connected MPCs based applications. A common characteristic to all SVPWM-based schemes is that the modulation algorithm is divided into three stages:

i) A set of switching states or vectors needs to be selected for modulation

ii) Computation of duty cycles of each vectors to achieve the desired reference over time average

iii) Sequence in which the vectors are generated.

Review suggests that SVPWM technique reduces the switching frequency, common mode voltage, THD, losses etc. Despite of having so many advantages the SVPWM technique is not dominant in industrial applications because of complicated real time implementation of above mention stages involved in SVPWM technique. Still SPWM technique is most used technique in the industries due to its less complexity in the implementation and low computational cost.

\section{Applications}

In this review some specific and important applications on BTB connection are presented which clearly shows that this technology is now capable enough to handle the pressure of fast moving technology in this area and this is only possible due to major development in multilevel topologies, modulation technology and control methodology[63-77]. Some important applications are tabulated in Table 5. to show the relevance of MPCs technology for the Back to Back connection along with their important feature.

Table 5

Recent Advances in Applications of MPCs connected Back to Back

\begin{tabular}{|c|c|c|c|}
\hline Area of Application & $\begin{array}{l}\text { Applications of Back to Back } \\
\text { connected MPCs }\end{array}$ & Rating & Important Features \\
\hline \multirow[t]{3}{*}{$\begin{array}{l}\text { Energy } \\
\text { System }\end{array}$} & Wind Energy $[6,63,76,77]$ & Upto 5MW & $\begin{array}{l}\text { It's simple, low cost and reliable } \\
\text { front end. }\end{array}$ \\
\hline & HVDC $[6,73]$ & 1000MW & $\begin{array}{l}\text { Improved efficiency \& power } \\
\text { system stability with reactive } \\
\text { power control }\end{array}$ \\
\hline & $\begin{array}{l}\text { Hydropumped energy storage } \\
\text { system[6] }\end{array}$ & $200 \mathrm{MVA}$ & $\begin{array}{l}\text { Improved efficiency \& power } \\
\text { system stability with reactive } \\
\text { power control }\end{array}$ \\
\hline Production & Regenerative Conveyors[63] & $\begin{array}{l}\text { Each drive } \\
\text { of } 2.5 \mathrm{MW}\end{array}$ & $\begin{array}{l}\text { Fully regenerative operation, low } \\
\text { input current harmonic content \& } \\
\text { adjustable input power factor. }\end{array}$ \\
\hline Transportation & propulsion & Each & Overall cost is reduced. \\
\hline
\end{tabular}


syste[61]

Variable Speed electric marine propulsion system[6]

Transrapid system[63,74,75] of $6.15 \mathrm{MW}$

$30 \mathrm{MW}$

12 converters units of 15.6 MVA
Power quality is improved

Regenerative braking and the power level of the application makes Back to Back connected MPCs an effective solution.

\section{Challenges \& Future Development}

Due to the advancement in the field of power electronics, the MPCs technology has reached to certain level of maturity with wide range of applications. Still there certain challenges before the Back to Back connected MPCs and these challenges are shown in Table 6 along with their benefits.

Table 6

Challenges before Back to Back connected MPCs

\begin{tabular}{|c|c|}
\hline Challenges & Benefits \\
\hline $\begin{array}{l}\text { Reduction of number of } \\
\text { variables to be sensed }\end{array}$ & $\begin{array}{l}\text { There will be an elimination of sensor offsets, size of converter system } \\
\text { also reduced, and system become noise insensitive \& economically } \\
\text { sound. }\end{array}$ \\
\hline $\begin{array}{l}\text { Power } \\
\text { Improvement } \quad \text { Quality } \\
\text { Power Factor })\end{array}$ & $\begin{array}{l}\text { Elimination of lower order harmonic with low voltage distortion and } \\
\text { high power factor at the input side. Reduction in filter size. }\end{array}$ \\
\hline $\begin{array}{l}\text { Reduction of Common } \\
\text { Mode Voltage }\end{array}$ & $\begin{array}{l}\text { Reliable operation of electric drive system. Less premature bearing } \\
\text { failures \& Low EMI. }\end{array}$ \\
\hline $\begin{array}{l}\text { Balancing of Neutral Point } \\
\text { Potential Voltage }\end{array}$ & $\begin{array}{l}\text { Reliable operation of power devices, Reduced voltage stressed across } \\
\text { the devices. Improved quality of voltage and current. }\end{array}$ \\
\hline Effective Control of MPCs & $\begin{array}{l}\text { Improved performance of the system in terms of power quality, } \\
\text { efficiency \& reliability. }\end{array}$ \\
\hline Packaging of MPCs & Reduced size and complexity. \\
\hline Switching losses & $\begin{array}{l}\text { Effective cooling system can be designed with improved power quality } \\
\& \text { overall efficiency }\end{array}$ \\
\hline $\begin{array}{l}\text { Fault } \\
\text { Capabilities }\end{array}$ & $\begin{array}{l}\text { Improved reliability \& performance as the fault tolerance capabilities } \\
\text { of NPC multilevel converter is poor. }\end{array}$ \\
\hline
\end{tabular}

\section{Conclusion}

This paper has reviewed the present state of the art of multilevel converter, connected Back to Back by presenting the most recent contribution on topologies, modulation \& high power applications. It is found that diode clamped topology is the topology used for the Back to Back connection. Lot of research has already been done which deals with control of Back to Back connected MPCs are presented in this paper, shows that still there is scope of improvement in the performance of MPCs connected Back to Back. Applications of Back to Back connected MPCs shows that now this technology has reached to certain level of maturity especially in the field of wind energy and high power AC drives. But existence of challenges before this technology indicates that still long way to go for this technology to gain remarkable achievement in the field of high power conversion.

\section{References}

[1]. Bhowmik, S.; Spee, R.; , "A guide to the application-oriented selection of AC/AC converter topologies," Applied Power Electronics Conference and Exposition, 1992. APEC '92. Conference Proceedings 1992., Seventh Annual , vol., no., pp.571-578, 23-27 Feb 1992

[2]. Bor-Ren Lin; Hsin-Hung Lu; Shuh-Chuan Tsay; , "Control technique for high power factor multilevel rectifier," Aerospace and Electronic Systems, IEEE Transactions on , vol.37, no.1, pp.226-241, Jan 2001

[3]. Moran, L.; Espinoza, J.; Ortiz, M.; Rodriguez, J.; Dixon, J.; , "Practical problems associated with the operation of ASDs based on active front end converters in power distribution systems," Industry Applications Conference, 2004. 39th IAS Annual Meeting. Conference Record of the 2004 IEEE, vol.4, no., pp. 2568- 2572 vol.4, 3-7 Oct. 2004

[4]. F. Auerbach, M. Glantschnig, A. Porst, J. G. Bauer, D. Reznik, H. J. Schulze, J. Gottert, M. Hierholzer, T. Schutze, and R. Spanke, "6.5-kV IGBT modules," in Conf. Rec. IEEE IAS Annu. Meeting, Phoenix, AZ, 1999, pp. 1770-1774.

[5]. J S Lai and F Z Peng. .Multilevel Converters . "A New Breed of Power Converters" IEEE Transactions on Industry Applications, vol 32, no 3, May/June 1996, pp 509-517. 
[6]. Kouro, S.; Malinowski, M.; Gopakumar, K.; Pou, J.; Franquelo, L.G.; Bin Wu; Rodriguez, J.; Pérez, M.A.; Leon, J.I.; , "Recent Advances and Industrial Applications of Multilevel Converters," Industrial Electronics, IEEE Transactions on , vol.57, no.8, pp.2553-2580, Aug. 2010

[7]. Franquelo, L.G.; Rodriguez, J.; Leon, J.I.; Kouro, S.; Portillo, R.; Prats, M.A.M.; , "The age of multilevel converters arrives," Industrial Electronics Magazine, IEEE, vol.2, no.2, pp.28-39, June 2008

[8]. C. Newton, M. Sumner, and T. Alexander, "Multi-level converters:A real solution to high voltage drives?" IEE Colloq. Dig., no. 1997/091,pp. 3/1-3/5, 1997.

[9]. L. M. Tolbert, F. Z. Peng, and T. G. Habetler, "Multilevel converters for large electric drives," IEEE Trans. Ind. Appl., vol. 35, no. 1, pp. 36-44, Jan./Feb. 1999.

[10]. Rodriguez, J.R.; Dixon, J.W.; Espinoza, J.R.; Pontt, J.; Lezana, P.; , "PWM regenerative rectifiers: state of the art," Industrial Electronics, IEEE Transactions on, vol.52, no.1, pp. 5- 22, Feb. 2005

[11]. Bhat, A.H.; Agarwal, P.; , "An Improved Performance Three-Phase Neutral-Point Clamped Rectifier with Simplified Control Scheme," Industrial Electronics, 2006 IEEE International Symposium on , vol.2, no., pp.1019-1024, 9-13 July 2006

[12]. A Pandey, B N Singh, A Chandra, K Al-Haddad, D P Kothari,” A Review of Multilevel Power Converters,” IE (I)-EL, vol. 86, pp no. 220-231, March 2006.

[13]. Rodriguez, J.; Jih-Sheng Lai; Fang Zheng Peng; , "Multilevel inverters: a survey of topologies, controls, and applications," Industrial Electronics, IEEE Transactions on , vol.49, no.4, pp. 724- 738, Aug 2002

[14]. W. McMurray, "Fast response stepped-wave switching power converter circuit," U.S. Patent 3581212 , May $25,1971$.

[15]. J. A. Dickerson and G. H. Ottaway, "Transformerless power supply with line to load isolation," U.S. Patent 3 596 369, Aug. 3, 1971.

[16]. R. H. Baker, "High-voltage converter circuit," U.S. Patent 4203 151, May 13, 1980.Nabae, I. Takahashi, and H. Akagi, “A new neutral-point-clamped PWM inverter," IEEE Trans. Ind. Appl., vol. IA-17, no. 5, pp. 518-523, Sep./Oct. 1981.R. H. Baker, "Bridge converter circuit," U.S. Patent 4270 163, May 26, 1981.

[17]. ABB. [Online]. Available: www.abb.com

[18]. SIEMENS. [Online]. Available: www.siemens.com

[19]. TMEIC-GE. [Online]. Available: www.tmeic-ge.com

[20]. Ansaldo Sistemi Industriali. [Online]. Available: www.asiansaldo.com

[21]. Converteam. [Online]. Available: www.converteam.com

[22]. Eaton. [Online]. Available: www.eaton.com

[23]. Arrowspeed. [Online]. Available: www.arrowspeed.com

[24]. Rongxin Power Electronic Co. (RXPE). [Online]. Available: www.rxpe.co.uk

[25]. LS Industrial Systems. [Online]. Available: http://eng.lsis.biz/

[26]. Yaskawa. [Online]. Available: www.yaskawa.eu.com

[27]. Beijing Leader \& Harvest Electric Technologies. [Online]. Available: www.ld- harvest.com

[28]. Schneider-Electric. [Online]. Available: www.schneider-electric.com

[29]. Alstom. [Online]. Available: www.alstom.com

[30]. Grupo Jema. [Online]. Available: www.grupojema.com

[31]. S. Rizzo and N. Zargari, "Medium voltage drives: What does the future hold?" in Proc. 4th IPEMC Conf., Aug. 14-16, 2004, vol. 1, pp. 82-89.

[32]. R. D. Klug and N. Klaassen, "High power medium voltage drives-Innovations, portfolio, trends," in Proc. Eur. Conf. Power Electron. Appl., 2005, pp. 1-10.

[33]. B. Wu, High-Power Converters and AC Drives. New York: Wiley-IEEE Press, Mar. 2006

[34]. J. Rodriguez, S. Bernet, B. Wu, J. O. Pontt, and S. Kouro, "Multilevel voltage-source-converter topologies for industrial mediumvoltage drives,” IEEE Trans. Ind. Electron., vol. 54, no. 6, pp. 2930-2945, Dec. 2007.

[35]. P. Steimer, "High power electronics, trends of technology and applications," in Proc. PCIM, Germany, May 2007.

[36]. J. Rodriguez, B. Wu, S. Bernet, N. Zargari, J. Rebolledo, J. Pontt, and P. Steimer, "Design and evaluation criteria for high power drives," in Conf. Rec. IEEE IAS Annu. Meeting, Oct. 5-9, 2008, pp. 1-9.

[37]. J. Rodriguez, L. G. Franquelo, S. Kouro, J. I. Leon, R. C. Portillo, M. A. M. Prats, and M. A. Perez, "Multilevel converters: An enabling technology for high-power applications," Proc. IEEE, vol. 97, no. 11, pp. 1786-1817, Nov. 2009.

[38]. D. Krug, S. Bernet, S. S. Fazel, K. Jalili, and M. Malinowski, "Comparison of 2.3-kv medium-voltage multilevel converters for industrial medium-voltage drives,” IEEE Trans. Ind. Electron., vol. 54, no. 6, pp. 2979-2992, Dec. 2007.

[39]. S. S. Fazel, S. Bernet, D. Krug, and K. Jalili, "Design and comparison of 4-kv neutral-point-clamped, flying-capacitor, and seriesconnected H-bridge multilevel converters,” IEEE Trans. Ind. Appl., vol. 43, no. 4, pp. 1032-1040, Jul./Aug. 2007.

[40]. Hefner, A.; Sei-Hyung Ryu; Hull, B.; Berning, D.; Hood, C.; Ortiz-Rodriguez, J.M.; Rivera-Lopez, A.; Tam Duong; Adwoa Akuffo; Hernandez-Mora, M.; , "Recent Advances in High-Voltage, High-Frequency Silicon-Carbide Power Devices," Industry Applications Conference, 2006. 41 st IAS Annual Meeting. Conference Record of the 2006 IEEE, vol.1, no., pp.330-337, 8-12 Oct. 2006

[41]. C Osawa, Y Matsumoto, T Mizukami and S Ozaki. .A State-space Modelling and a Neutral Point Voltage Control for an NPC Power Converter.. Proceedings on IEEE PCC-Nagaoka.97, pp 225-230.

[42]. Y Chen and B T Ooi. .Multimodular Multilevel Rectifier/inverter Link with Independent Reactive Power Control.. IEEE Power Delivery, vol 13, July1998, pp 902-908.

[43]. N Celanovic and D Boroyevich. .A Comprehensive Study of Neutralpoint Voltage Balancing Problem in Three-level Neutral Point Clamped Voltage Source PWM Inverters.. IEEE Transactions on Power Electron, vol 15, March 2000, pp 242-249.

[44]. Tekwani, P.N.; Kanchan, R.S.; Gopakumar, K.; , "A Dual Five-Level Inverter-Fed Induction Motor Drive With Common-Mode Voltage Elimination and DC-Link Capacitor Voltage Balancing Using Only the Switching-State Redundancy-Part II," Industrial Electronics, IEEE Transactions on , vol.54, no.5, pp.2609-2617, Oct. 2007

[45]. D Zhou and D Rouaud. .Experimental Comparisons of Space Vector Neutral Point Balancing Strategies for Three-level Topology.. Proceedings on IEEE PESC.99, pp 1071-1076.

[46]. M. Saeedifard, R. Iravani, and J. Pou, "A space vector modulation strategy for a back-to-back five-level HVDC converter system," IEEE Trans. Ind. Electron., vol. 56, no. 2, pp. 452-466, Feb. 2009.

[47]. Hatti, N.; Kondo, Y.; Akagi, H.;, "Five-Level Diode-Clamped PWM Converters Connected Back-to-Back for Motor Drives," Industry Applications, IEEE Transactions on , vol.44, no.4, pp.1268-1276, July-aug. 2008.

[48]. Ishida, T.; Matsuse, K.; Sugita, K.; Lipei Huang; Sasagawa, K.; , "DC voltage control strategy for a five-level converter," Power Electronics, IEEE Transactions on, vol.15, no.3, pp.508-515, May 2000 
[49]. Chaves, M.; Margato, E.; Silva, J.F.; Pinto, S.F.; , "On the problem of balancing the DC capacitor voltage divider in back-to-back multilevel converters," Industrial Electronics, 2009. IECON '09. 35th Annual Conference of IEEE , vol., no., pp.694-699, 3-5 Nov. 2009

[50]. Pou, J.; Pindado, R.; Boroyevich, D.; Rodriguez, P.; , "Limits of the neutral-point balance in back-to-back-connected three-level converters," Power Electronics, IEEE Transactions on , vol.19, no.3, pp. 722- 731, May 2004

[51]. Chaturvedi P.K.; Jain Shailendra ; Agrawal Pramod;" "A simple carrier-based neutral point potential regulator for three-level diode clamped inverter," International Journal of Power Electronics 2011 - Vol. 3, No.1 pp. 1 - 25

[52]. Natchpong, H.; Kondo, Y.; Akagi, H.; "Back-to-Back Connected Five-Level Diode-Clamped PWM Converters for Motor Drives," Power Conversion Conference - Nagoya, 2007. PCC '07, vol., no., pp.1456-1463, 2-5 April 2007

[53]. Leon, J.I.; Vazquez, S.; Sanchez, J.A.; Portillo, R.; Franquelo, L.G.; Carrasco, J.M.; Dominguez, E.; , "Conventional Space-Vector Modulation Techniques Versus the Single-Phase Modulator for Multilevel Converters," Industrial Electronics, IEEE Transactions on , vol.57, no.7, pp.2473-2482, July 2010

[54]. Grigoletto, F.B.; Pinheiro, H.; "A space vector PWM modulation scheme for back-to-back three-level diode-clamped converters," Power Electronics Conference, 2009. COBEP '09. Brazilian, vol., no., pp.1058-1065, Sept. 27 2009-Oct. 12009

[55]. Andler, D.; Kouro, S.; Perez, M.; Rodriguez, J.; Bin Wu; , "Switching loss analysis of modulation methods used in neutral point clamped converters," Energy Conversion Congress and Exposition, 2009. ECCE 2009. IEEE, vol., no., pp.2565-2571, 20-24 Sept. 2009

[56]. Minshull, S.R.; Bingham, C.M.; Stone, D.A.; Foster, M.P.; , "Frequency reduction schemes for back-to-back connected, diodeclamped multilevel converters," Power Electronics, IET, vol.3, no.1, pp.65-74, January 2010

[57]. Francisco J. Rodriguez, Santiago Cobreces, Emilio J. Bueno, Alvaro Hernandez, Raul Mateos, Felipe Espinosa, Control electroni c platform based on floating-point DSP and FPGA for a NPC multilevel back-to-back converter, Electric Power Systems Research, Volume 78, Issue 9, September 2008, Pages 1597-1609

[58]. Minshull, S.R.; Bingham, C.M.; Stone, D.A.; Foster, M.P.; , "A new switching scheme for reduced switching frequency and balanced capacitor voltages for back-to-back connected, diode-clamped multilevel converters," Power Electronics, Machines and Drives, 2008. PEMD 2008. 4th IET Conference on , vol., no., pp.636- 639, 2-4 April 2008

[59]. Zhiguo Pan; Fang Zheng Peng;, "A Sinusoidal PWM Method With Voltage Balancing Capability for Diode-Clamped Five-Level Converters," Industry Applications, IEEE Transactions on , vol.45, no.3, pp.1028-1034, May-june 2009

[60]. Jing Zhao; Xiangning He; Rongxiang Zhao; , "A Novel PWM Control Method for Hybrid-Clamped Multilevel Inverters," Industrial Electronics, IEEE Transactions on, vol.57, no.7, pp.2365-2373, July 2010

[61]. Rodriguez, J.; Franquelo, L.G.; Kouro, S.; Leon, J.I.; Portillo, R.C.; Prats, M.A.M.; Perez, M.A.; , "Multilevel Converters: An Enabling Technology for High-Power Applications," Proceedings of the IEEE, vol.97, no.11, pp.1786-1817, Nov. 2009

[62]. F. Blaabjerg, Z. Chen, and S. B. Kjaer, "Power electronics as efficient interface in dispersed power generation systems," IEEE Trans. Power Electron., vol. 19, no. 5, pp. 1184-1194, Sep. 2004.

[63]. M. Malinowski, S. Stynski, W. Kolomyjski, and M. P. Kazmierkowski, "Control of three-level PWM converter applied to variablespeed-type turbines,” IEEE Trans. Ind. Electron., vol. 56, no. 1, pp. 69-77, Jan. 2009.

[64]. S. Alepuz, S. Busquets-Monge, J. Bordonau, J. Gago, D. Gonzalez, and J. Balcells, "Interfacing renewable energy sources to the utility grid using a three-level inverter," IEEE Trans. Ind. Electron., vol. 53, no. 5, pp. 1504-1511, Oct. 2006.

[65]. R. C. Portillo, M. M. Prats, J. I. Leon, J. A. Sanchez, J. M. Carrasco, E. Galvan, and L. G. Franquelo, "Modeling strategy for backto-back three-level converters applied to high-power wind turbines," IEEE Trans. Ind. Electron., vol. 53, no. 5, pp. 1483-1491, Oct. 2006

[66]. M. Winkelnkemper, F. Wildner, and P. K. Steimer, "6 MVA five-level hybrid converter for windpower," in Proc. IEEE Power Electron. Spec.Conf., Jun. 15-19, 2008, pp. 4532-4538.

[67]. M. Winkelnkemper, F. Wildner, and P. Steimer, "Control of a 6 MVA hybrid converter for a permanent magnet synchronous generator for windpower," in Proc. 18th ICEM, Sep. 6-9, 2008, pp. 1-6.

[68]. S. Alepuz, S. Busquets-Monge, J. Bordonau, J. A. Martinez-Velasco, C. A. Silva, J. Pontt, and J. Rodriguez, "Control strategies based on symmetrical components for grid-connected converters under voltage dips," IEEE Trans. Ind. Electron., vol. 56, no. 6, pp. 2162-2173, Jun. 2009.

[69]. C. H. Ng, M. A. Parker, L. Ran, P. J. Tavner, J. R. Bumby, and E. Spooner, "A multilevel modular converter for a large, light weight wind turbine generator," IEEE Trans. Power Electron., vol. 23, no. 3, pp. 1062-1074, May 2008.

[70]. B. Gemmell, J. Dorn, D. Retzmann, and D. Soerangr, "Prospects of multilevel VSC technologies for power transmission," in Proc.IEEE/PES T\&D Conf. Expo., Apr. 21-24, 2008, pp. 1-16.

[71]. S. Allebrod, R. Hamerski, and R. Marquardt, "New transformerless, scalable modular multilevel converters for HVDCtransmission," in Proc. IEEE Power Electron. Spec. Conf., Jun. 15-19, 2008, pp. 174-179.

[72]. J. Helmer, U. Henning, P. Kamp, and J. Nothhaft, “Advanced converter module for high speed maglev system transrapid," in Proc. 9th EPE, Graz, Austria, 2001, p. 10.

[73]. U. Henning, R. Hoffmann, and J. Hochleitner, "Advanced static power converter and control components for TRANSRAPID maglev system," in Proc. PCC Osaka, Apr. 2-5, 2002, vol. 3, pp. 1045-1049.

[74]. Faulstich, A.; Stinke, J.K.; Wittwer, F.; , "Medium voltage converter for permanent magnet wind power generators up to 5 MW," Power Electronics and Applications, 2005 European Conference on , vol., no., pp.9 pp.-P.9,2005

[75]. Bueno, E.J.; Cobreces, S.; Rodriguez, F.J.; Hernandez, A.; Espinosa, F.; , "Design of a Back-to-Back NPC Converter Interface for Wind Turbines With Squirrel-Cage Induction Generator," Energy Conversion, IEEE Transactions on , vol.23, no.3, pp.932-945, Sept. 2008 